\title{
Short communication: Hair cortisol concentrations in Holstein-Friesian and crossbreed $F_{1}$ heifers
}

\author{
T. Peric,${ }^{*}$ A. Comin,${ }^{* 1}$ M. Corazzin, $\dagger$ M. Montillo, ${ }^{*}$ A. Cappa, $\ddagger$ G. Campanile,$\S$ and A. Prandi* \\ *Department of Food Science, University of Udine, via Sondrio 2, 33100 Udine, Italy \\ †Department of Agricultural and Environmental Sciences, University of Udine, via delle Scienze 206, 33100 Udine, Italy \\ ‡Evoluzione S.r.l., via S. Sepolcro 29, 36040 Sossano (VI), Italy \\ §Department of Zootechnical Science and Food Inspectione, University of Napoli Federico II, via Delpino 1, 80137 Napoli, Italy
}

\begin{abstract}
The aim of this study was to evaluate the hypothalamic-pituitary-adrenal (HPA) axis activity of HolsteinFriesian and crossbreed $\mathrm{F}_{1}$ heifers by analysis of the cortisol concentrations in hair samples. Cortisol, the primary hormone of the HPA axis, is the biological endpoint for the investigation of the HPA response. The study was conducted on 290 prepubertal heifers; 142 heifers were pure Holstein-Friesian and 148 were crossbreed $F_{1}$ heifers obtained from the 3-way rotational system with Swedish Red and Montbéliarde breeds. Extraction was performed on the hair using methanol, and cortisol concentrations were determined by a radioimmunoassay method. Cortisol concentrations measured in regrown hair of crossbreed $\mathrm{F}_{1}$ heifers were significantly lower than those in hair of Holstein-Friesian heifers. This result helps us to better understand the differences in HPA activity and allostatic load between Holstein-Friesian and crossbreed $\mathrm{F}_{1}$ heifers and allows us to better assess the adaptability of these animals to the environment and the importance of crossbreed traits for profitability in dairy farming.

Key words: Holstein-Friesian, crossbreed, hair, cortisol
\end{abstract}

\section{Short Communication}

Several researchers indicate that the welfare of purebred dairy cows has been compromised by high selection pressures that, in recent years, have increased the rate of inbreeding for most breeds. To date, the inbreeding coefficient in the Holstein-Friesian breed varies between 4 and 6\% (World Holstein Friesian Federation, 2011). This value reflects inbreeding depression and underscores the observed deterioration of functional traits such as fertility, health, calving ease, and longevity due

Received September 12, 2012.

Accepted January 25, 2013.

${ }^{1}$ Corresponding author: antonella.comin@uniud.it to antagonistic genetic correlations between functional and production traits (Rauw et al., 1998; Mark, 2004; Miglior et al., 2005). Another important issue associated with high inbreeding rates is the increased frequency of recessive lethal diseases (Kristensen and Sørensen, 2005), such as bovine leukocyte adhesion deficiency (BLAD) and complex vertebral malformation (CVM) in Holsteins.

This observation has led to a search for a solution, and in recent years, it has been suggested that crossbreeding, a technique that has been used extensively with great success in beef cattle, pig, rabbit, and poultry production systems but has not yet been used for dairy cattle breeding (Sørensen et al., 2008), may help to overcome these problems.

Crossbreeding is the mating of individuals from different lines, breeds or populations. As described by Sørensen et al. (2008), 2 main reasons exist for applying crossbreeding within livestock. The first is to utilize the different additive genetic levels between breeds to generate offspring with better economic ability caused by new combinations of additive genetic components. The second is that crosses between pure lines or breeds express heterosis, the effects of which tend to be greater on functional traits such as fertility, calving ease, and robustness (Touchberry, 1992; Heins, 2007). Crossbreed animals respond better to environmental changes and stressors and are more economically efficient compared with the parental breeds (Mäki-Tanila, 2007).

Crossbreeding may also affect activation of the hypothalamic-pituitary-adrenal (HPA) axis, which results in a cascade of endocrine responses that aid in coping with stressors and the maintenance of allostasis. Cortisol, the primary hormone of this axis, is an appropriate biological endpoint in the investigation of HPA axis function and has been used to assess stress and welfare in farm animals (Mormède et al., 2007).

Cortisol levels are routinely determined from blood (Negrão et al., 2004; Probo et al., 2011), feces (Möstl et al., 2002), urine (Ferranti et al., 2011), milk (Gygax et al., 2006), and saliva (Negrão et al., 2004). These 
methods provide a measurement of the cortisol concentration at a single point in time or within $12 \mathrm{~h}$ (Palme et al., 1996).

Hair cortisol analysis is a complementary means of monitoring the HPA axis, as it reflects cortisol secretion over longer periods. In this way, it is possible to detect long-term cortisol concentrations, which can be associated with chronic stress (Kalra et al., 2007). Unlike previous methods, the analysis of cortisol in hair is unaffected by circadian variations in the hormone or by factors inducing short-term variations.

The collection of hair is simple and noninvasive, and the sample does not decompose like other body fluids or tissues (Baliková, 2005). Hair is a relatively stable medium known to incorporate blood-borne hormones through passive diffusion from blood capillaries present on the basement membrane during its active growth phase (Pragst and Balikova, 2006), and these hormones may remain detectable for a long time (Kintz et al., 2006; Webb et al., 2010). In humans (Ito et al., 2005; Slominski et al., 2005, 2006) and guinea pigs (Keckeis et al., 2012), cortisol synthesis in the skin (melanocytes, keratinocytes) is described; therefore, it remains an open question whether the cortisol concentration in hair reflects that in the peripheral circulation or local production (or both). To our knowledge, there are no data concerning local production of cortisol in ruminants. However, when evaluating the results, the rate of hair growth and the depth of the hair bulb should be taken into account. Three key factors influence the incorporation in the hair are the melanin content of hair and the lipophilicity and basicity of the substance. Lipophilic (uncharged) organic molecules can easily penetrate membranes and diffuse according to the concentration gradient in matrix cells (Pragst and Balikova, 2006).

The interest in hair focuses mainly on the fact that, unlike other biological matrices, hair provides long-term information that allows us to reconstruct the history of the individual from a few months before sampling. Shaving and resampling of hair in the same area allows monitoring of the cortisol levels for weeks or months prior. This phenomenon allows us to retrospectively examine cortisol production without needing to take samples at multiple time points (Kirschbaum et al., 2009; Russell et al., 2012).

Hair has long been used in toxicology, forensic science, doping control, and other fields as a biological matrix for the detection of environmental agents, drugs, or toxins (Kirschbaum et al., 2009). Raul et al. (2004) demonstrated the detection of endogenous concentrations of cortisol and cortisone in human hair. In recent years, quantification of hair cortisol has been used for clinical applications in humans (Gow et al.,
2010; Thomson et al., 2010). Cortisol measurement in hair samples has been already reported as a validated method in cows (Comin et al., 2011; del Rosario González-de-la-Vara et al., 2011).

Taking into account that crossbreeds have higher fertility and health than purebred animals (and that this superiority has not been fully investigated) and knowing that the HPA axis is involved in maintenance of homeostasis, reproduction, immunity, inflammatory processes, growth, and brain functions, the purpose of this study was to evaluate the HPA axis activity of Holstein-Friesian and crossbreed $F_{1}$ heifers by analysis of cortisol levels in hair.

\section{Animals and Hair Samples}

Although hair sampling is a noninvasive procedure, the study was carried out in accordance with EU Directive 2010/63/EU for animal experiments. After weaning, at approximately 4 mo of age, 295 heifers belonging to 2 breeds, Holstein-Friesian $(\mathrm{n}=145)$ and crossbreed $\mathrm{F}_{1}$ (obtained from the 3 -way rotational system with Swedish Red and Montbéliarde; $\mathrm{n}=150$ ), were randomly chosen; average BW was $131.1 \pm 0.53 \mathrm{~kg}$ (mean $\pm \mathrm{SE})$ and was similar between breeds.

From 4 to 8 mo of age, the animals underwent the same management, had not been subjected to changes in group, and were loose-housed with straw bedding $\left(3.5 \mathrm{~m}^{2} /\right.$ head $)$. Heifers were offered, ad libitum, a haybased diet containing $13 \% \mathrm{CP}$ and $5.80 \mathrm{MJ}$ of $\mathrm{NE}_{\mathrm{L}} /$ $\mathrm{kg}$ of DM, calculated in accordance with the INRA standard (Vermorel, 1988). During the experimental period, the animals were subjected to periodic clinical examinations. Two animals were removed for suspected coccidiosis and 3 for skin lesions because in a previous study we detected a significant positive correlation between hair cortisol concentrations and the clinical condition of animals(Comin et al., 2013).

Three months before hair collection (5 mo of age), we shaved the sampling area widely and completely. Then, hair samples were collected at 8 mo of age from the same area (Comin et al., 2012). This allowed us to collect only regrowth hair because the hair of dairy cows grows approximately 0.6 to $1 \mathrm{~cm} / \mathrm{mo}$ and animals undergo a full molt approximately every 3 mo (Schwertl et al., 2003). Samples of hair used in the experiment were collected in April (monthly average temperature $=12.4^{\circ} \mathrm{C}$ ) when the animals were 8 mo of age.

All samples were collected on the same day. White hair samples were carefully taken from the animal's forehead with clippers; at this time, the single hairs collected were at different physiological phases (anagen, catagen, and telogen). Consequently, these samples reflected the hormone concentrations of at least $1 \mathrm{mo}$ 
before the start of the experiment. The hair samples were stored in dry tubes at room temperature until analysis.

To avoid stress and remain in compliance with current legislation on animal welfare, samples were collected during routine farm activities.

\section{Hair Cortisol Assay}

Hair extraction was performed using methanol, and the cortisol levels were determined by the RIA method as described by Comin et al. (2011). Briefly, the hair strands were washed in $5 \mathrm{~mL}$ of isopropanol, as suggested by Davenport et al. (2006), and the hair cortisol was extracted according to the method described by Koren et al. (2002) with the following modifications: $60 \mathrm{mg}$ of trimmed hair was put in a glass vial with 3 $\mathrm{mL}$ of methanol. The vials were incubated at $37^{\circ} \mathrm{C}$ for $18 \mathrm{~h}$. Next, the liquid in the vial was evaporated to dryness at $37^{\circ} \mathrm{C}$ under an airstream suction hood. The remaining residue was dissolved in $0.6 \mathrm{~mL}$ of $\mathrm{PBS}, 0.05$ $M, \mathrm{pH} 7.5$.

Hair cortisol levels were measured using a solid-phase microtiter RIA assay. In brief, a 96-well microtiter plate (Optiplate, Perkin-Elmer Life Science, Boston, MA) was coated with goat anti-rabbit $\gamma$-globulin serum diluted 1:1,000 in $0.15 \mathrm{~m} M$ sodium acetate buffer, $\mathrm{pH}$ 9 , and the plate was incubated overnight at $4^{\circ} \mathrm{C}$. The plate was then washed twice with RIA buffer, $\mathrm{pH}$ 7.4, and incubated overnight at $4^{\circ} \mathrm{C}$ with $200 \mu \mathrm{L}$ of the anti-cortisol serum diluted 1:12,000. The rabbit anticortisol antibody used was obtained from Biogenesis (Poole, UK). Cross-reactivities of this antibody with other steroids are as follows: cortisol $100 \%$, corticosterone $1.8 \%$, and aldosterone $<0.02 \%$. After washing the plate with RIA buffer, standards (5-300 pg/well), a quality control extract, the test extracts $(10 \mathrm{mg})$, and tracer (hydrocortisone; Perkin-Elmer Life Sciences) were added, and the plate was incubated overnight at $4^{\circ} \mathrm{C}$. Bound hormone was separated from free hormone by decanting and washing the wells in RIA buffer. After addition of $200 \mu \mathrm{L}$ of scintillation cocktail, the plate was counted on a $\beta$-counter (Top-Count, Perkin-Elmer Life Sciences). Intra- and interassay CV were 3.6 and 9.8\%, respectively. The sensitivity of the assay, calculated as the interpolated dose of the response to a concentration of zero minus the statistical error, was $1.23 \mathrm{pg} /$ well. To determine the parallelism between cortisol standards and endogenous cortisol in cows, hair samples containing high concentrations of endogenous cortisol $(100 \mu \mathrm{L})$ were serially diluted in $0.05 \mathrm{M} \mathrm{PBS}, \mathrm{pH} 7.5$, to obtain volumes of 50, 25, and $10 \mu \mathrm{L}$. The relationship between hair cortisol concentrations and the standard cortisol curve determined through linear regression was linear: the correlation coefficient (r) was 0.99 and the model was given by the equation $\mathrm{y}=0.96 \mathrm{x}+5.572$; the slope of the line was 0.96 .

\section{Statistical Analysis}

Statistical analysis was performed using the free software R (version 2.14.1; http://www.R-project.org). Normality of data distribution was tested using the Shapiro-Wilk test. The difference between hair cortisol levels of Holstein-Friesian and crossbreed $\mathrm{F}_{1}$ heifers was tested using a Mann-Whitney U nonparametric test.

Cortisol levels were determined in 290 hair samples. No significant differences were observed in the length of the regrown hair between groups. Statistical analysis revealed that hair cortisol concentrations measured in crossbreed $\mathrm{F}_{1}$ heifers were significantly lower $(P<$ 0.01) than those recorded in Holstein-Friesian heifers. Medians with minimum and maximum recorded values for hair cortisol levels of Holstein-Friesian heifers and crossbreed $\mathrm{F}_{1}$ heifers are described in Table 1.

As claimed by different authors (Christensen and Pedersen, 1988; Mäki-Tanila, 2007; Sørensen et al., 2008), crossbreed animals overcome inbreeding problems, are more robust, and are better adapted to problems related to animal health and welfare.

The HPA axis is a neuroendocrine system primarily involved in metabolic homeostasis and the regulation of metabolic energy fluxes and stress responses (Mormède et al., 2007). We investigated the activity of this axis by analyzing cortisol levels in hair of prepubertal heifers (Table 1).

Hair cortisol levels in both Holstein-Friesian and crossbreed $F_{1}$ heifers were found to be higher than those observed in our previous studies (Comin et al., 2011), which were performed on healthy dairy cows during summer grazing. Higher levels of cortisol in heifers may be due to several stressors, including weaning

Table 1. Medians (minimum-maximum) of hair cortisol concentrations of Holstein-Friesian and crossbreed $\mathrm{F}_{1}$ Holstein heifers

\begin{tabular}{lcc}
\hline Item & Holstein-Friesian & Crossbreed \\
\hline Heifers (no.) & 142 & 148 \\
Cortisol (pg/mg of hair) & $5.38^{\mathrm{A}}(1.91-27.95)$ & $4.40^{\mathrm{B}}(2.11-41.74)$ \\
\hline
\end{tabular}

$\overline{\mathrm{A}, \mathrm{B}}$ Medians with unlike superscripts differ significantly at $P<0.01$. 
and the prepubertal and pubertal periods. It has also been observed that calves, similarly subjected to many stressors, have greater hair cortisol concentrations than cows (Comin et al., 2008; del Rosario González-de-laVara et al., 2011).

Pure Holstein-Friesian and crossbreed $F_{1}$ heifers showed individual cortisol values as listed in Table 1, highlighting that the response of an organism to maintain allostasis is individual. In fact, numerous environmental and genetic factors can increase an individual's exposure to cortisol (Golden et al., 2011). For instance, the bioavailability of corticosteroid hormones may result from genetic factors (Désautés et al., 2002; Remer et al., 2008), inherent adrenal sensitivity to adrenocorticotropic hormone, or levels of corticosteroid-binding globulin (Gagliardi et al., 2010), $11 \beta$-hydroxysteroid dehydrogenase enzymes (Seckl, 2004), and glucocorticoid receptor levels (Nicolaides et al., 2010). Individual variation can also arise from environmental influences in utero, during the early postnatal stage, or as a result of experiences later in life (Mormède et al., 2007; Scharf and Schmidt, 2012).

In our study, despite individual variability, the crossbreed $\mathrm{F}_{1}$ heifers showed a median cortisol value that was significantly lower $(P<0.01)$ than that of the pure Holstein-Friesian heifers. It is known that individuals with the highest levels of HPA axis activity will have the highest allostatic load (Charney, 2004). In contrast, individuals with lower, but not depressed, HPA axis activity will be characterized by a more resilient profile (Charney, 2004). Crossbreed animals were found to be more economically efficient compared with the parental breeds (Mäki-Tanila, 2007) and could be characterized by greater resilience to stressors. A study in young men examined the relationship between resilience (measured using the Resilience Scale for Adults) and HPA axis reactivity, pointing out that highly resilient individuals secrete less cortisol than less resilient individuals, but that phenomenon is not conductive to lower HPA axis reactivity (Mikolajczak et al., 2008). This characteristic could be very advantageous when the cow is in a biologically stressful state, such as during active milk production.

In conclusion, crossbreed $F_{1}$ heifers showed lower concentrations of cortisol than the Holstein-Friesian heifers. This result helps us to better understand the differences in HPA activity and allostatic load between Holstein-Friesian and crossbreed $\mathrm{F}_{1}$ heifers..

\section{REFERENCES}

Baliková, M. 2005. Hair analysis for drugs of abuse. Plausibility of interpretation. Biomed. Pap. Med. Fac. Univ. Palacky Olomouc Czech Repub. 149:199-207.
Charney, D. S. 2004. Psychobiological mechanisms of resilience and vulnerability: Implications for successful adaptation to extreme stress. Am. J. Psychiatry 161:195-216.

Christensen, L. G., and J. Pedersen. 1988. Crossbreeding of Dairy Cattle: 650th Report from the National Institute of Animal Science. Landhusholdningsselskabets forlag, København, Denmark.

Comin, A., T. Peric, M. Corazzin, M. C. Veronesi, T. Meloni, V Zufferli, G. Cornacchia, and A. Prandi. 2013. Hair cortisol as a marker of hypothalamic-pituitary-adrenal axis activation in Friesian dairy cows clinically or physiologically compromised. Livest. Sci. 152:36-41. http://dx.doi.org/10.1016/j.livsci.2012.11.021.

Comin, A., A. Prandi, T. Peric, M. Corazzin, S. Dovier, and S. Bovolenta. 2011. Hair cortisol levels in dairy cows from winter housing to summer highland grazing. Livest. Sci. 138:69-73.

Comin, A., L. Tidu, G. Cornacchia, A. Cappa, B. Renaville, and A. Prandi. 2008. Neonatal period and hair cortisol in cattle as a marker of stress. Pages 221-225 in Proc. 16th Congr. Mediterranean Federation for Health and Production of Ruminants, Zadar, Croatia. Faculty of Veterinary Medicine Zagreb, Croatian Veterinary Chamber, Zagreb.

Comin, A., M. C. Veronesi, M. Montillo, M. Faustini, S. Valentini, F. Cairoli, and A. Prandi. 2012. Hair cortisol levels as a retrospective marker of hypothalamic-pituitary-adrenal axis activity in horse foals. Vet. J. 194:131-132.

Davenport, M. D., S. Tiefenbacher, C. K. Lutz, M. A. Novak, and J. S. Meyer. 2006. Analysis of endogenous cortisol concentrations in the hair of rhesus macaques. Gen. Comp. Endocrinol. 147:255-261.

del Rosario González-de-la-Vara, M. R., R. A. Valdez, V. LemusRamirez, J. C. Vázquez-Chagoyán, A. Villa-Godoy, and M. C. Romano. 2011. Effects of adrenocorticotropic hormone challenge and age on hair cortisol concentrations in dairy cattle. Can. J. Vet. Res. 75:216-221.

Désautés, C., J. P. Bidanelt, D. Milant, N. Iannuccelli, Y. Amigues, F. Bourgeois, J. C. Caritez, C. Renard, C. Chevalet, and P. Mormède. 2002. Genetic linkage mapping of quantitative trait loci for behavioral and neuroendocrine stress response traits in pigs. J. Anim. Sci. 80:2276-2285.

Ferranti, C., F. D. Quadri, L. Palleschi, C. Marchiafava, M. Pezzolato, E. Bozzetta, M. Caramelli, and R. Draisci. 2011. Studies on the presence of natural and synthetic corticosteroids in bovine urine. Steroids 76:616-625.

Gagliardi, L., J. T. Ho, and D. J. Torpy. 2010. Corticosteroid-binding globulin: The clinical significance of altered levels and heritable mutations. Mol. Cell. Endocrinol. 316:24-34.

Golden, S. H., G. S. Wand, S. Malhotra, I. Kamel, and K. Horton. 2011. Reliability of hypothalamic-pituitary-adrenal axis assessment methods for use in population-based studies. Eur. J. Epidemiol. 26:511-525.

Gow, R., S. Thomson, M. Rieder, S. Van Uum, and G. Koren. 2010. An assessment of cortisol analysis in hair and its clinical applications. Forensic Sci. Int. 196:32-37.

Gygax, L., I. Neuffer, C. Kaufmann, R. Hauser, and B. Wechsler. 2006 Milk cortisol concentration in automatic milking systems compared with auto-tandem milking parlors. J. Dairy Sci. 89:3447-3454.

Heins, B. J. 2007. Impact of an old technology on profitable dairying in the 21st century. Pages 7-19 in Crossbreeding of Dairy Cattle: The Science and the Impact; 4th Biennial W. E. Petersen Symposium, University of Minnesota, St. Paul. Department of Animal Science, University of Minnesota, St. Paul.

Ito, N., T. Ito, A. Kromminga, A. Bettermann, M. Takigawa, F. Kees, R. H. Straub, and R. Paus. 2005. Human hair follicles display a functional equivalent of the hypothalamic-pituitary-adrenal axis and synthesize cortisol. FASEB J. 19:1332-1334.

Kalra, S., A. Einarson, T. Karaskov, S. Van Uum, and G. Koren. 2007. The relationship between stress and hair cortisol in healthy pregnant women. Clin. Invest. Med. 30:E103-E107.

Keckeis, K., M. Lepschy, H. Schöpper, L. Moser, J. Troxler, and R. Palme. 2012. Hair cortisol: A parameter of chronic stress? Insights from a radiometabolism study in guinea pigs. J. Comp. Physiol. B 182:985-996. 
Kintz, P., M. Villain, and V. Cirimele. 2006. Hair analysis for drug detection. Ther. Drug Monit. 28:442-446.

Kirschbaum, C., A. Tietze, N. Skoluda, and L. Dettenborn. 2009. Hair as a retrospective calendar of cortisol production-Increased cortisol incorporation into hair in the third trimester of pregnancy. Psychoneuroendocrinology 34:32-37.

Koren, L., O. Mokady, T. Karaskov, J. Klein, G. Koren, and E. Gleffen. 2002. A novel method using hair for determining hormonal levels in wildlife. Anim. Behav. 63:403-406.

Kristensen, T. N., and A. C. Sørensen. 2005. Inbreeding-Lessons from animal breeding, evolutionary biology and conservation genetics. Anim. Sci. 80:121-133.

Mäki-Tanila, A. 2007. An overview on quantitative and genomic tools for utilizing dominance genetic variation in improving animal production. J. Agric. Food Sci. 16:188-198.

Mark, T. 2004. Applied genetic evaluations for production and functional traits in dairy cattle. J. Dairy Sci. 87:2641-2652.

Miglior, F., B. L. Muir, and B. J. Van Doormaal. 2005. Selection indices in Holstein cattle of various countries. J. Dairy Sci. 88:12551263.

Mikolajczak, M., E. Roy, O. Luminet, and P. de Timary. 2008. Resilience and hypothalamic-pituitary-adrenal axis reactivity under acute stress in young men. Stress 11:477-482.

Mormède, P., S. Andanson, B. Aupérin, B. Beerda, D. Guémené, J. Malmkvist, X. Manteca, G. Manteuffel, P. Prunet, C. G. van Reenen, S. Richard, and I. Veissier. 2007. Exploration of the hypothalamic-pituitary-adrenal function as a tool to evaluate animal welfare. Physiol. Behav. 92:317-339.

Möstl, E., J. L. Maggs, G. Schrötter, U. Besenfelder, and R. Palme. 2002. Measurement of cortisol metabolites in faeces of ruminants. Vet. Res. Commun. 26:127-139.

Negrão, J. A., M. A. Porcionato, A. M. de Passillé, and J. Rushen. 2004. Cortisol in saliva and plasma of cattle after ACTH administration and milking. J. Dairy Sci. 87:1713-1718.

Nicolaides, N. C., Z. Galata, T. Kino, G. P. Chrousos, and E. Charmandari. 2010. The human glucocorticoid receptor: Molecular basis of biologic function. Steroids 75:1-12.

Palme, R. P. Fischer, H. Schildorfer, and M. N. Ismail. 1996. Excretion of infused ${ }^{14} \mathrm{C}$-steroid hormones via faeces and urine in domestic livestock. Anim. Reprod. Sci. 43:43-63.

Pragst, F., and M. A. Balikova. 2006. State of the art in hair analysis for detection of drug and alcohol abuse. Clin. Chim. Acta 370:17-49.

Probo, M., A. Comin, F. Cairoli, M. Faustini, H. Kindahl, I. De Amicis, and M. C. Veronesi. 2011. Selected metabolic and hormonal profiles during maintenance of spontaneous ovarian cysts in dairy cows. Reprod. Domest. Anim. 46:448-454.

Raul, J. S., V. Cirimele, B. Ludes, and P. Kintz. 2004. Detection of physiological concentrations of cortisol and cortisone in human hair. Clin. Biochem. 37:1105-1111.
Rauw, W. M., E. Kanis, E. N. Noordhuizen, and F. J. Grommers. 1998. Undesirable side effects of selection for high production efficiency in farm animals: A review. Livest. Prod. Sci. 56:13-33.

Remer, T., C. Maser-Gluth, and S. A. Wudy. 2008. Glucocorticoid measurements in health and disease-metabolic implications and the potential of 24-h urine analyses. Mini Rev. Med. Chem. 8:153-170.

Russell, E., G. Koren, M. Rieder, and S. Van Uum. 2012. Hair cortisol as a biological marker of chronic stress: Current status, future directions and unanswered questions. Psychoneuroendocrinology 37:589-601.

Scharf, S. H., and M. V. Schmidt. 2012. Animal models of stress vulnerability and resilience in translational research. Curr. Psychiatry Rep. 14:159-165.

Schwertl, M., K. Auerswald, and H. Schnyder. 2003. Reconstruction of the isotopic history of animal diets by hair segmental analysis. Rapid Commun. Mass Spectrom. 17:1312-1318.

Seckl, J. R. 2004. 11 ß-Hydroxysteroid dehydrogenases: Changing glucocorticoid action. Curr. Opin. Pharmacol. 4:597-602.

Slominski, A., B. Zbytek, A. Szczesniewski, I. Semak, J. Kaminski, T. Sweatman, and J. Wortsman. 2005. CRH stimulation of corticosteroids production in melanocytes is mediated by ACTH. Am. J. Physiol. Endocrinol. Metab. 288:E701-E706.

Slominski, A., B. Zbytek, M. Zmijewski, R. M. Slominski, S. Kauser, J. Wortsman, and D. J. Tobin. 2006. Corticotropin releasing hormone and the skin. Front. Biosci. 11:2230-2248.

Sørensen, M. K., E. Norberg, J. Pedersen, and L. G. Christensen. 2008. Invited review: Crossbreeding in dairy cattle: A Danish perspective. J. Dairy Sci. 91:4116-4128.

Thomson, S., G. Koren, L. A. Fraser, M. Rieder, T. C. Friedman, and S. H. Van Uum. 2010. Hair analysis provides a historical record of cortisol levels in Cushing's syndrome. Exp. Clin. Endocrinol. Diabetes 118:133-138.

Touchberry, R. W. 1992. Crossbreeding effects in dairy cattle: The Illinois experiment, 1949 to 1969. J. Dairy Sci. 75:640-667.

Vermorel, M. 1988. Nutrition energetique. Pages 57-74 in Alimentation des Bovins, Ovins et Caprins. R. Jarrige, ed. INRA, Paris, France.

Webb, E., S. Thomson, A. Nelson, C. White, G. Koren, M. Rieder, and S. Van Uum. 2010. Assessing individual systemic stress through cortisol analysis of archaeological hair. J. Archaeol. Sci. 37:807812

World Holstein Friesian Federation. 2011. A WHFF view on inbreeding in Holstein cattle. http://www.euholsteins.com/info/ documents/InbreedinginHolsteinCattle.pdf. 